\title{
A Case of Isolated Duodenal Varices Secondary to Chronic Pancreatitis with Review of Literature
}

\author{
Venugopala Bommana ${ }^{\mathrm{a}}$, Prasun Shah ${ }^{\mathrm{b}, \mathrm{c}}$, Michael Kometa ${ }^{\mathrm{a}}$, Rawan Narwal ${ }^{\mathrm{a}}$, Prashant Sharma ${ }^{\mathrm{a}}$
}

\begin{abstract}
An unusual case of upper gastrointestinal hemorrhage due to an isolated varix involving the 2 nd part of the duodenum is presented here. The varix was the result of Chronic Pancreatitis induced the superior mesenteric vein obstruction. The diagnosis was made preoperatively by upper gastrointestinal endoscopy and selective mesenteric angiogram. Patient was treated successfully with Mesocaval shunt surgery between the superior mesenteric vein and the inferior vena cava using a $10 \mathrm{~mm}$ Dacron graft. This is the unique case showing hemorrhagic complication of Chronic Pancreatitis due to the superior mesenteric vein obstruction.
\end{abstract}

Keywords: Isolated duodenal varices; Hemorrhagic complications of pancreatitis; Hemetemesis; Superior mesenteric vein obstruction

\section{Introduction}

Chronic pancreatitis is a major health hazard and since long we know different complications due to it. Here we have presented a case of isolated duodenal varices which we found incidentally in our patient who has presented with hemetemesis and at the end of long investigational battery we found that patient has superior mesenteric obstruction secondary to adhesions in the peripancreatic region. In literature there are very few cases reported showing bleeding duodenal varices,

Manuscript accepted for publication November 22, 2010

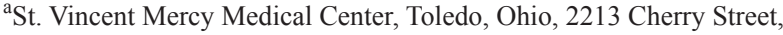
Toledo, Ohio 43608, USA

${ }^{\mathrm{b}}$ St. Vincent Charity Hospital, Cleveland, Ohio, 2351 East 22nd Street, Cleveland, OH 44115, USA

${ }^{\mathrm{c} C}$ Corresponding author: shahprasun@yahoo.com
}

doi:10.4021/gr249w most of them are in the duodenal bulb which are part of portal hypertension. In our patient there was no evidence found for portal hypertension and duodenal varices were in the second portion of the duodenum. Patient had superior mesenteric obstruction secondary to chronic pancreatitis which is the unique presentation of the complication.

\section{Case Report}

A 33 years old Caucasian male presented to the emergency room of St.Vincent Mercy Medical Center at Toledo, Ohio with a history of intermittent hemetemesis for last couple of weeks which has increased in severity during the last 24 hours, progressing to 4 episodes of a cup full of blood. He also had complaints of light headedness and dizziness. He had no history of hemetochezia, melena, fever, chills, constipation, diarrhea, abdominal pain or nausea. He had no recent NSAIDs use, headache, chest pain, shortness of breath or palpitation.

Patient had past history of Diabetes Mellitus type 1 and is on Insulin. Patient had history significant for Gallstone pancreatitis which resulted in Pseudocyst formation. Patient had undergone Cholecystectomy and Cystojejunostomy in 2007. He had history of Spinal Stenosis, right knee surgery and Tonsillectomy. Patient was allergic to Avandia, Fentanyl, and Metfromin. Patient was on Tramadol, Neurontin, Insulin, Zolpidem and Omeprazole. Patient had no history of Gastrointestinal (GI) disease in family. His father had diabetes and mother had COPD and pernicious anemia. Patient was a non smoker, non alcoholic and denied using any illicit drugs. His bowel and bladder functions were unaltered.

On presentation his vitals were Temp: $36.3{ }^{\circ} \mathrm{C}$, Pulse: 114/min, Blood pressure: 102/54 mm of Hg, Oxygen saturation: $99 \%$ on room air and Respiratory rate: $16 / \mathrm{min}$. On physical examination he was conscious, coherent, pale looking and weak with warm and moist skin without dermatosis. No signs of Jaundice or generalized Lymphadenopathy were found. He had no obvious spinal or limb deformities. He had normal pulses in all extremities without any signs of cyanosis. His oral cavity was normal without ulcerations. His chest was symmetrically expanding with good breath sounds 


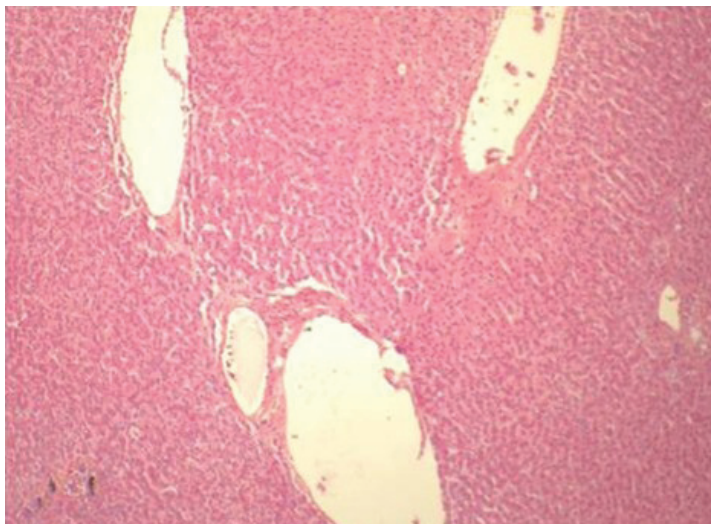

Figure 1. Liver Biopsy showing normal architecture

and without labored breathing. He had adynamic precordium with apex beat located in 5th intercostal space at midclavicular line. He had normal heart sounds without any murmur. His abdomen was soft and flat. He had tenderness in epigastric region. No organomegaly or masses were found and bowel sounds were normal. Patient had normal neurological examination with grossly intact cranial nerves and normal reflexes. Pupils were equal and reacting to light normally.

His initial investigations were Hemoglobin $6.3 \mathrm{gm} / \mathrm{dl}$, Hematocrit of 18.7\%, MCV: $88.8 \mathrm{fL}$, White cell count $8.4 \mathrm{k} /$ ul (Neutrophils 84, Lymphocytes 10, Monocytes 6, Eosinophils 0, Basophils 0), Platelet count: 327 k/ul, Sodium: 137 meq/l, Potassium: $4.7 \mathrm{mEq} / 1$, Bicarbonate: $24.5 \mathrm{mEq} / 1$, Chloride: $103 \mathrm{mEq} / \mathrm{l}$, Blood Urea Nitrogen: $35 \mathrm{mg} / \mathrm{dl}$, Creatinine: $0.59 \mathrm{mg} / \mathrm{dl}$, Glucose: $231 \mathrm{mg} / \mathrm{dl}$, Bilirubin: Direct: 0.12 and total $0.28 \mathrm{mg} / \mathrm{dl}$, Proteins total: $4.4 \mathrm{~g} / \mathrm{dl}$, Albumin: $2.7 \mathrm{~g} / \mathrm{dl}$, AST: 31 units/L, ALT: 44 units/l, Calcium: $7.9 \mathrm{mEq} / 1$, Alkaline phosphatase: 53 units/l, Lipase: 23 units/l, $\mathrm{pCO}_{2} 46, \mathrm{pO}_{2}$ 84, pH 7.34, PTT: 23.4 (20.3-30.9 sec), Prothrombin time: 12.5 (9.7-12 sec), INR: 1.2, Fibrinogen: 420(140-420 mg/ dl). Hepatitis serology and ANA screen were negative. He had undergone Liver biopsy was performed during surgery which was found normal without any changes of cirrhosis of liver (Fig. 1).

On upper GI endoscopy (EGD) esophageal and stomach mucosa were found normal without any active sites of bleeding. Fundus was clearly seen without varices. Pylorus was patent and the duodenal bulb was normal. The major papilla was identified in the descending duodenum and had normal appearance. Just distal to the major papilla in the 2nd portion of duodenum, there was a large submucosal bulge suspicious for an ectopic duodenal varix (Fig. 2). On withdrawal of the scope findings were confirmed.

Abdominal and pelvic CT scan with contrast showed massive gastric distention. Gastric outlet obstruction was suspected. Pancreatic Pseudocyst in the tail of the pancreas had significantly increased in size from the previous study.

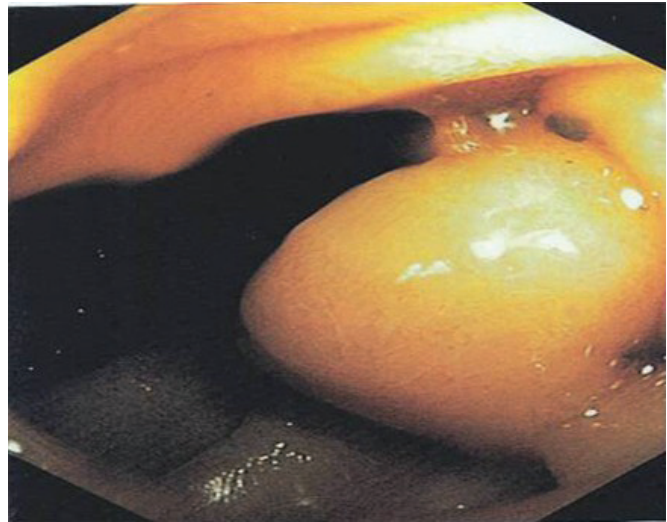

Figure 2. Duodenal varix in EGD

Changes of chronic pancreatitis were present.

Mesenteric Arteriogram showed slow contrast filling of the superior mesenteric vein with significant limiting of flow. Superior Mesenteric Vein obstruction was suspected. Multiple venous varicosities around the distal stomach and the pancreatic head region were found (Fig. 3). Possibility of at least partial thrombosis of the Superior Mesenteric Vein (SMV) near the pancreatic head region was suspected secondary to pancreatitis. Splenic vein was found of normal caliber without any varicosities.

Patient had undergone end to side Mesocaval Anastomosis with a Dacron $10 \mathrm{~mm}$ graft between the Superior Mesenteric Vein and the Inferior Vena Cava along with adhesionolysis and liver biopsy. During surgery no varicosities found in the gastric and esophageal region or no dilation found in the splenic or inferior mesenteric venous system. There

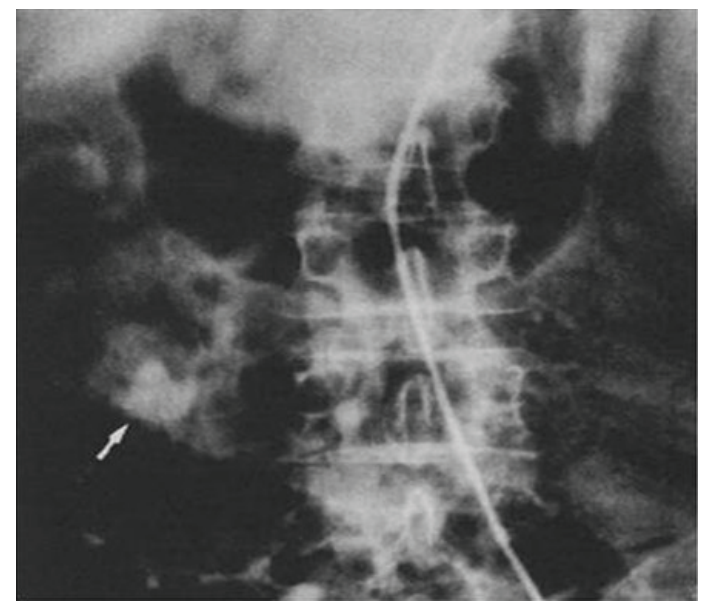

Figure 3. Venous phase of the superior mesenteric artery injection showing varices in the region of the duodenum 
were multiple adhesions found in the tail region of pancreas possibly because of previous Cystojejunostomy in that area. Similarly many adhesions found in the peripancreatic region most likely due to changes of chronic pancreatitis. Patient was discharged without any complications and found asymptomatic in the follow up visits with normal hemoglobin level and without any evidence of bleeding. Considering the young age of the patient and relatively absent varices at other sites Mesocaval shunt surgery was chosen as a treatment over Transjugular Intrahepatic Portosystemic Shunt (TIPS) and duodenal resection.

\section{Discussion}

Duodenal varices were initially recognized as a source of gastrointestinal hemorrhage by Alberti who described the radiologic findings in three cases in $1931[1,2]$. Since then approximately 105 cases has been noted in the literature. Out of them in our knowledge one case is been reported for the pancreatitis induced small bowel varices by Brian et al in 1992 [3]. Most of the cases reported for isolated duodenal varices were referable to Portal Hypertension, approximately $30 \%$ of them are resulting from cirrhosis of liver [4-6]. These percentages vary geographically as evidenced by AlMofarreh's series of 13 patients with Schistosomiasis [7]. Other important and rare etiologies of Duodenal varices are mentioned in Table 1.

Duodenal varices have a high bleeding rate and a recent review of 16 reported Cases showed that 12 patients $(75 \%)$ had massive hemorrhage (mean $10.4+3.8$ units of blood) and required emergency surgery. Interestingly, $75 \%$ of patients in this review had previous episodes of gastrointestinal hemorrhage, thus raising the possibility that duodenal varices have a tendency to rebleed [17-19].
Duodenal varices are considered dilated veins of Retzius around the pancreaticoduodenal region [20, 21]. Duodenal varices usually consist of a single vessel with associated afferent and efferent vessels which form a retroperitoneal portosystemic shunt $[21,22]$. The afferent vessel arises either from the superior or inferior pancreaticoduodenal vein or from the SMV $[21,22]$. The efferent vessel is thought to arise from one of the many retroperitoneal veins and commonly drains into the inferior vena cava. The varices usually lie in the posterior wall of the duodenal bulb [20, 21]. Distribution of varices in different areas of the duodenum and its association with varices in other regions is presented in Table 2. According to available data most common site of varices in duodenum is duodenal bulb followed by second part of the duodenum.

We hypothesize that the bouts of pancreatitis led to progressive fibrosis of the peri pancreatic tissues and eventual occlusion of the Splenic and Superior Mesenteric veins [3]. Esophagogastric varices usually result from Splenic vein thrombosis and development of portosystemic collaterals in the short gastric veins. This is commonly called "left-sided portal hypertension" or "Sinistral Hypertension" [24-26]. Occlusion of the portal vein from pancreatitis can then lead to generalized portal hypertension and subsequent esophageal or gastric variceal bleeding [3, 24, 25]. Thrombosis of the superior mesenteric vein may lead to elevated splanchnic venous pressure and the potential for variceal bleeding, although this complication has not been reported previously $[3,24,25,27-29]$. In patients with pancreatitis, SMV occlusion may result from the progression of the fibrosis to the peri pancreatic tissues [3, 24, 25, 27-29]. Most patients, however, do not have bleeding complications, and the diagnosis of mesenteric vein occlusion is usually made during exploratory laparotomy for other reasons or on pre-operative angiography for other complications of pancreatitis [3, 24,

Table 1. Etiology of Duodenal varices in world Literatures

\author{
Cirrhosis of Liver [1,4-6] \\ Thrombotic disorders and Coagulopathies [4] \\ Schistosomiasis [7] \\ Pancreatitis and Cholangitis [3,8] \\ Omphalophlebitis (surgical catheterization of Umbilicus in adults) [8-10] \\ Pancreatic and periportal tumors [8] \\ Mesenteric Metastasis [4,11] \\ Surgical Procedure or Trauma [4,11] \\ Visceral Hemangiomata (Klippel-Trenaunay-Weber syndrome) [12-16] \\ Vascular Anomalies (Occlusion of SMV by abnormal Ileocecal Artery) [12-16] \\ Retroperitoneal Fibrosis [8]
}


Table 2. Review of Cases of Duodenal Varices [23]

\begin{tabular}{llc}
\hline Part of Duodenum & Duodenal Bulb & 48 \\
& 2nd portion & 12 \\
& 3rd portion & 3 \\
& 4th portion & 1 \\
& DuodenoJejunal Junction & 3 \\
& Not Specified & 38 \\
& & \\
Associated Varices & Esophagus & 25 \\
& Esophagus and Stomach & 2 \\
& Esophagus, Stomach and & 1 \\
& Jejunum & 5 \\
& Not recognized & 72 \\
\hline
\end{tabular}

\section{5, 27-29].}

Diagnosis of duodenal varices is almost always made during endoscopy for investigation of GI bleeding [4]. The diagnosis has also been made on barium studies, spleenoportography, angiography and laparotomy [4, 30]. It is not unusual to use more than one of these modalities to confirm the diagnosis. When duodenal varices are diagnosed by endoscopy, $60 \%$ have varices elsewhere in the GI tract and $50 \%$ of these are gastoresophageal. $40 \%$ of patients with portal hypertension have duodenal varices at angiography. But they are clinically not so significant because they rarely penetrate the submucosa [30-32]. CT scan with contrast and MRI are not routinely used for the diagnosis of ectopic varices [29]. Ultrasound and color duplex has some informative and diagnostic values when blood flow is more than $5 \mathrm{~cm} /$ second. Though its efficacy in diagnosis of intra-abdominal ectopic varices is not known and usefulness in investigation of Upper GI bleeding is to be evaluated [33, 34]. Some reports mention its use in diagnosis of patency of shunt following shunt surgeries.

Capsule endoscopy (CE) has revolutionized examination of the small bowel. Currently, the most common indication for CE is GI bleeding of obscure etiology [12]. For this indication, the yield of CE is reportedly about $67 \%[12$, 35]. The most common findings include angioectasia, fresh blood, ulceration, tumor and varices. The mucosal color of small bowel varices may differ minimally from that of the surrounding mucosa [12, 35-37]. Technetium scintigraphy is been used in some cases for diagnosis of GI bleeding and needs further evaluation. Selective mesenteric angiography and spleenoportography have sensitivity of $50 \%[19,32]$.
Angiographic and spleenoportographic examination are helpful though, in that it will clearly define the anatomy, which may include duodenal and esophageal components, and proves useful in planning the operative approach [19, 32].

Treatment of small bowel variceal bleeding is directed toward relieving the segmental elevated pressures and is based upon the etiology of the varices [3]. Treatments of bleeding from ectopic varices include local treatment performed endoscopically, radiologically, surgically with portal decompressive surgery or TIPS [38]. The efficacy of pharmacological treatment with beta blockers has never been evaluated [38]. Endoscopic sclerotherapy has been tried for duodenal, anorectal and gastric varices but almost invariably rebleeding occurred and ulcers following sclerotherapy may result in life threatening hemorrhage [39, 40]. Variceal embolization after portal vein catheterization can control bleeding but rebleeding is not unusual due to the development of new collaterals feeding the ectopic varices [38, 41]. Surgical ligation of varices is also a temporary measure that does not allow definitive control of variceal bleeding; this is not surprising as none of these methods relieves the portal hypertension [42]. Balloon Temponade in case of varices in the second portion of duodenum is out of question.

TIPS is a hemodynamic equivalent of a side to side small diameter Portocaval shunt, it is much less invasive than surgery and can be performed even in patients with decompensated liver disease [38, 43-45]. TIPS has been widely used for the treatment of bleeding from gastoresophageal varices as well as refractory ascites. This procedure is safe with a $1-2 \%$ incidence of life threatening complications. The rate of hepatic encephalopathy is much lower than Portocaval shunt surgery. Shunt dysfunction due to progressive stenosis following pseudointimal hyperplasia inside the stent is a significant problem. Accordingly shunt function must be followed closely with duplex Doppler ultrasound [43-49]. Shunt catheterization and angiographic interventions are frequently needed. The use of stents covered with PTFE has been reported to markedly reduce the incidence of shunt stenosis and will probably represent a major advance in the future [41].

Portocaval shunt surgery has been used in some patients however the postoperative morbidity and mortality rates are high particularly in patients with decompensated liver disease [50]. Decompressive surgery is very efficient at stopping the rebleeding but it may precipitate liver failure or induce recurrent hepatic encephalopathy $[34,43]$. In patients with bleeding secondary to portal hypertension treatment consists of portosystemic shunting and resection of the variceal segment $[34,50]$.

Our patient was treated successfully with Mesocaval shunt surgery [50]. In our case patient was young and had elevated pressure in the Splanchnic Circulation secondary to obstruction of the Superior Mesenteric vein. And as only 
superior mesenteric vein was narrowed due to chronic pancreatitis without other evidences of portal hypertension TIPS was not considered. We performed shunt surgery instead of resection of the 2 nd part of the duodenum as we believed that resecting the affected portion was difficult due to presence of adhesions and did not offer complete solution in this case. In comparison we found that relieving the segmental pressure was a better option.

\section{References}

1. Alberti W.Uber den rontgenologischen Nachweise von Varizen in Bulbus duoodeni. Forschr Geb Rontgenstr 1931;43:60-65.

2. Alberti W.Uber den rontgenologischen Nachweise von Varizen in Bulbus duoodeni. Forschr Geb Rontgenstr 1933;4:467-469.

3. Lein BC, McCombs PR. Bleeding varices of the small bowel as a complication of pancreatitis: case report and review of the literature. World J Surg 1992;16(6):11471149; discussion 1150.

4. Cottam DR, Clark R, Hayn E, Shaftan G. Duodenal varices: a novel treatment and literature review. Am Surg 2002;68(5):407-409.

5. Amin R, Alexis R, Korzis J. Fatal ruptured duodenal varix: a case report and review of literature. Am J Gastroenterol 1985;80(1):13-18.

6. Hashizume M, Tanoue K, Ohta M, Ueno K, Sugimachi K, Kashiwagi M, Sueishi K. Vascular anatomy of duodenal varices: angiographic and histopathological assessments. Am J Gastroenterol 1993;88(11):1942-1945.

7. Al-Mofarreh M, Al-Moagel-Alfarag M, Ashoor T, Shadoochy F. Duodenal varices. Report of 13 cases. Z Gastroenterol 1986;24(11):673-680.

8. Linder S, Wiechel KL. Duodenal varicose veins. Surg Endosc 1991;5(1):31-35.

9. Brown KM, Kaplan MM, Donowitz M. Extrahepatic portal venous thrombosis: frequent recognition of associated diseases. J Clin Gastroenterol 1985;7(2):153-159.

10. Itzchak Y, Glickman MG. Duodenal varices in extrahepatic portal obstruction. Radiology 1977;124(3):619624.

11. Khouqeer F, Morrow C, Jordan P. Duodenal varices as a cause of massive upper gastrointestinal bleeding. Surgery 1987;102(3):548-552.

12. Tang SJ, Zanati S, Dubcenco E, Cirocco M, Christodoulou D, Kandel G, Haber GB, et al. Diagnosis of smallbowel varices by capsule endoscopy. Gastrointest Endosc 2004;60(1):129-135.

13. Lieberman DA, Krippaehne WW, Melnyk CS. Colonic varices due to intestinal cavernous hemangiomas. Dig Dis Sci 1983;28(9):852-858.

14. Miller LS, Barbarevech C, Friedman LS. Less frequent causes of lower gastrointestinal bleeding. Gastroenterol Clin North Am 1994;23(1):21-52.

15. Garrett L, Carrier O, Jr., Douglas BH. Effects of reserpine on blood pressure and vascular electrolytes in hypertension. Eur J Pharmacol 1967;2(3):236-238.

16. Darwish K, Bleau BL. Extensive small bowel varices as a cause of severe anemia in Klippel-Trenaunay-Weber syndrome. Am J Gastroenterol 1998;93(11):2274-2275.

17. Chandra-Sekhar HB, Alstead EM, Kumar PJ, Farthing MJ. Duodenal varices. A neglected cause of massive, recurrent gastrointestinal bleeding. Dig Dis Sci 1992;37(3):449-451.

18. Kunert H, Ottenjann R. Endoscopy in bleeding duodenal varices. Endoscopy 1976; 8:99-101.

19. Wilson SE, Stone RT, Christie JP, Passaro E, Jr. Massive lower gastrointestinal bleeding from intestinal varices. Arch Surg 1979;114(10):1158-1161.

20. Ibukuro K, Tsukiyama T, Mori K, Inoue Y. Veins of Retzius at CT during arterial portography: anatomy and clinical importance. Radiology 1998;209(3):793-800.

21. Lopera JE, Arthurs B, Scheuerman C, Sandoz C, Petersosn S, Castaneda-Zuniga W. Bleeding duodenal: varices treatment by TIPS and transcatheter embolization. Cardiovasc Intervent Radiol 2008;31(2):431-434.

22. Gray H, Anatomy of the Human Body 20th edition. Lea and Febiger New York and Philadelphia 1918:680-682.

23. Tanaka T, Kato K, Taniguchi T, Takagi D, Takeyama N, Kitazawa Y. A case of ruptured duodenal varices and review of the literature. Jpn J Surg 1988;18(5):595-600.

24. Moossa AR, Gadd MA. Isolated splenic vein thrombosis. World J Surg 1985;9(3):384-390.

25. Longstreth GF, Newcomer AD, Green PA. Extrahepatic portal hypertension caused by chronic pancreatitis. Ann Intern Med 1971;75(6):903-908.

26. Schwartz SL. Surgical disease of the liver. New York: McGraw-Hill 1964;291-294.

27. Warshaw AL, Jin GL, Ottinger LW. Recognition and clinical implications of mesenteric and portal vein obstruction in chronic pancreatitis. Arch Surg 1987;122(4):410415.

28. Loveless S, Gammill SL. Focal pancreatitis and superior mesenteric vein thrombosis. J Tenn Med Assoc 1987;80(7):423-424.

29. Vogelzang RL, Gore RM, Anschuetz SL, Blei AT. Thrombosis of the splanchnic veins: CT diagnosis. AJR Am J Roentgenol 1988;150(1):93-96.

30. Stephen G. Miething R. Rontgen diagnostic varicoses duodenal varanderungen bei protaler hypertension. Der Radiologe 1968;3:90-95.

31. Lebrec D, Benhamou JP. Ectopic varices in portal hypertension. Clin Gastroenterol 1985;14(1):105-121.

32. Sauerbruch T, Weinzierl M, Dietrich HP, Antes G, Eisenburg J, Paumgartner G. Sclerotherapy of a bleeding duodenal varix. Endoscopy 1982;14(5):187-189. 
33. Verbanck JJ, Rutgeerts LJ, Haerens MH, Tytgat JH, Segaert MF, Tytgat HJ, Afschrift MB. Partial splenoportal and superior mesenteric venous thrombosis. Early sonographic diagnosis and successful conservative management. Gastroenterology 1984;86(5 Pt 1):949-952.

34. Sukigara M, Koyama I, Komazaki T, Matsuda T, Ishii T, Omoto R. Bleeding varices located in the second portion of the duodenum. Jpn J Surg 1987;17(2):130-135.

35. Ginsberg GG, Barkun AN, Bosco JJ, Isenberg GA, Nguyen CC, Petersen BT, Silverman WB, et al. Wireless capsule endoscopy: August 2002. Gastrointest Endosc 2002;56(5):621-624.

36. Iddan G, Meron G, Glukhovsky A, Swain P. Wireless capsule endoscopy. Nature 2000;405(6785):417.

37. Tang SJ, Zanati S, Dubcenco E, Christodoulou D, Cirocco M, Kandel G, Kortan P, et al. Capsule endoscopy regional transit abnormality: a sign of underlying small bowel pathology. Gastrointest Endosc 2003;58(4):598602.

38. Vidal V, Joly L, Perreault P, Bouchard L, Lafortune M, Pomier-Layrargues G. Usefulness of transjugular intrahepatic portosystemic shunt in the management of bleeding ectopic varices in cirrhotic patients. Cardiovasc Intervent Radiol 2006;29(2):216-219.

39. Kishimoto K, Hara A, Arita T, Tsukamoto K, Matsui N, Kaneyuki T, Matsunaga N. Stomal varices: treatment by percutaneous transhepatic coil embolization. Cardiovasc Intervent Radiol 1999;22(6):523-525.

40. Jonnalagadda SS, Quiason S, Smith OJ. Successful therapy of bleeding duodenal varices by TIPS after failure of sclerotherapy. Am J Gastroenterol 1998;93(2):272-274.

41. Bureau C, Garcia-Pagan JC, Otal P, Pomier-Layrargues G, Chabbert V, Cortez C, Perreault P, et al. Improved clinical outcome using polytetrafluoroethylene-coated stents for TIPS: results of a randomized study. Gastroenterology 2004;126(2):469-475.

42. Sarfeh IJ, Rypins EB. The emergency portacaval H graft in alcoholic cirrhotic patients: influence of shunt diameter on clinical outcome. Am J Surg 1986;152(3):290-
293.

43. Casado M, Bosch J, Garcia-Pagan JC, Bru C, Banares R, Bandi JC, Escorsell A, et al. Clinical events after transjugular intrahepatic portosystemic shunt: correlation with hemodynamic findings. Gastroenterology 1998;114(6):1296-1303.

44. Pomier-Layrargues G, Villeneuve JP, Deschenes M, Bui B, Perreault P, Fenyves D, Willems B, et al. Transjugular intrahepatic portosystemic shunt (TIPS) versus endoscopic variceal ligation in the prevention of variceal rebleeding in patients with cirrhosis: a randomised trial. Gut 2001;48(3):390-396.

45. Lafortune M, Martinet JP, Denys A, Patriquin H, Dauzat M, Dufresne MP, Colombato L, et al. Short- and longterm hemodynamic effects of transjugular intrahepatic portosystemic shunts: a Doppler/manometric correlative study. AJR Am J Roentgenol 1995;164(4):997-1002.

46. Hidajat N, Stobbe H, Hosten N, Schroeder RJ, Fauth M, Vogl T, Felix R. Transjugular intrahepatic portosystemic shunt and transjugular embolization of bleeding rectal varices in portal hypertension. AJR Am J Roentgenol 2002;178(2):362-363.

47. Fantin AC, Zala G, Risti B, Debatin JF, Schopke W, Meyenberger C. Bleeding anorectal varices: successful treatment with transjugular intrahepatic portosystemic shunting (TIPS). Gut 1996;38(6):932-935.

48. Morris CS, Najarian KE. Transjugular intrahepatic portosystemic shunt for bleeding stomal varices associated with chronic portal vein occlusion: long-term angiographic, hemodynamic, and clinical follow-up. Am J Gastroenterol 2000;95(10):2966-2968.

49. Bernstein D, Yrizarry J, Reddy KR, Russell E, Jeffers L, Schiff ER. Transjugular intrahepatic portosystemic shunt in the treatment of intermittently bleeding stomal varices. Am J Gastroenterol 1996;91(10):2237-2238.

50. Isaksson B, Jeppsson B, Bengtsson F, Hannesson P, Herlin P, Bengmark S. Mesocaval shunt or repeated sclerotherapy: effects on rebleeding and encephalopathy--a randomized trial. Surgery 1995;117(5):498-504. 